\title{
Synthesis, Identification, and Biological Study for Some Complexes of Azo Dye Having Theophylline
}

\author{
Hasan Mohammed \\ Chemistry Department, Science College, University of Al-Qadisiyah, Al Diwaniyah, Iraq \\ Correspondence should be addressed to Hasan Mohammed; hasan.sh.mohemmed@qu.edu.iq
}

Received 24 March 2021; Revised 19 June 2021; Accepted 9 July 2021; Published 22 July 2021

Academic Editor: Nirmal Kumar Sarkar

Copyright ( 2021 Hasan Mohammed. This is an open access article distributed under the Creative Commons Attribution License, which permits unrestricted use, distribution, and reproduction in any medium, provided the original work is properly cited.

This article includes the synthesis of heterocyclic azo dye of theophylline by coupling diazonium salt of 4-chloroaniline with theophylline which is, namely, 8-(1-(4-chlorophenyl)azo)theophylline (CPAT). The complexes of cobalt and nickel were prepared by reacting their ions with CPAT ligand in ethanol under 1:2 ratio metal-ligand. The CPAT ligand and its complexes were characterized by elemental analysis, infrared spectrometry, electronic absorption spectroscopy, molar conductivity, and magnetic moment. The cobalt and nickel complexes show octahedral geometry having general formula $\left[\mathrm{M}(\mathrm{CPAT})_{2} \mathrm{Cl}_{2}\right]$. This article addresses the properties of CPAT dye such as photochromic properties. The CPAT dye exhibited obvious and desired changes under irradiation with visible light ( $405 \mathrm{~nm}$ ), high sensitive for $\mathrm{pH}$ changes which refer to its ability to be analysis indicator. CPAT dye exhibited solvatochromic properties presenting red shift with polar solvent. The CPAT and its complexes show interesting antibiological activities towards Staph. aureus and E. coli bacteria and Aspergillus fungi.

\section{Introduction}

The azo function $(-\mathrm{N}=\mathrm{N}-)$ in the ligands appears intense color within the visible area and is sensitive for the changes in the acidity $(\mathrm{pH})$ that leads to the use of the ligands of this function as colorant for the tissue and indicators in analytical chemistry [1-4]. Azo dyes exhibit stereoisomerism under the light. The trans isomer is stable which converts to cis isomer under the light, when the process is perfectly reversible calling photochromic [5]. When this process is accompanied by a significant change in the dipole moment, that qualifies the material to be a candidate for high optic data storage [6]. The azo dye complexes such as azo quinoline dye and its complexes and rhenium complex based on the azo dye of iminopyridine exhibited significant nonlinear optical properties, and these properties play an important role in optical data storage and telecommunications [7-9].

The azo dyes have been received big attention as reagents to extract and determine the trace amount of metal ions in different samples [10-12]. Azo dye complexes were studied extensively due to their interesting properties and their applications such as catalysts, antimicrobials, colorants, corrosion inhibitors, and anticancer [13-15]. Azo complexes such as sulfamethoxazole azo dyes [16] and pyrazole azo complexes [17] exhibited interesting activities towards tuberculosis.

The complexes of the azo dye of 2,6-diaminopyridine showed a significant efficiency against Escherichia coli and Staphylococcus. On the other hand, these complexes exhibited high inhibitory activity against breast cancer (CMCF7 cell line) with high-interest $\mathrm{IC}_{50}$ which was $3.5-7.0 \mu \mathrm{gmL}^{-1}[10]$. Azo dyes are used for the treatment of viral infections, for example, in the presence of Direct Red 23 (azo dye), the ability of the virus to bind to the CD4 glycoprotein inhibits. Bismarck brown dye is used for the qualitative detection of $\mathrm{Sb}^{+3}$ ion. Azo dyes and azo dye complexes are used as photosensitizers [18] such as ruthenium complexes with the azo dye of quinolone exhibiting anticancer potential because they show significant activity in photodynamic therapy at long wavelength [19]. Azo dyes and azo dye complexes are used as photosensitizers in twophoton photodynamic therapy for the treatment of cancer because they exhibit low toxicity in dark conditions and a high yield for reactive oxygen species and are suitable for two-photon absorption [20,21]. 
The high pi acidity of N-heterocycles of azo dyes gives stability for the range of oxidation states of metal ions. Large amounts of azo dyes are added to food products to totalize the appearance and nutritional properties [22, 23]. Azo dyes and their complexes such as azo dye chromium (III) especially with acid dye exhibited large uses as dying in writing ink, toners for photocopiers, and dying for leather and hair [24]. Due to those applications of the azo dyes in industry, medicine, and spectroscopic analysis, we are interested in the preparation of azo dye of theophylline and its complexes with positive divalent ions of cobalt and nickel and study their spectroscopic and biological properties.

\section{Experimental}

2.1. Material and Methods. All reagents and solvents are from Sigma Aldrich except for theophylline which is supplied from $\mathrm{CDH}$ Company. Melting points of azo dye of theophylline and its complexes were recorded by electrothermal apparatus. Elemental analysis of CHN was done on Vario EIIII CHN analyser. Infrared spectra of CPAT ligand and the complexes were done on a Perkin-Elmer, using $\mathrm{KBr}$ disks. ${ }^{1} \mathrm{H}-\mathrm{NMR}$ spectrum of CPAT dye was done in DMSOd6 by Bruker Avance II spectrometer. LC-MS spectra of our compounds were carried out on LCMS 2010, Shimadzu mass analyser. The measurements of molar conductivity for synthesized complexes of CPAT dye were achieved on an ELICO CM-180 conductivity bridge in DMSO $\left(10^{-3} \mathrm{M}\right)$. The measurements of magnetic moment were done at room temperature using MSB balance. Electronic spectra were done by Shimadzu-1800.

Synthesis of azo dye of theophylline (CPAT) : the solution of 4-chloroaniline $(1.0 \mathrm{~g}, 7.8 \mathrm{mmole})$ was mixed with $6 \mathrm{~mL} \mathrm{HCl}(12 \mathrm{~N})$, and then the acidic aqueous solution of 4chloroaniline was cooled at $0-5^{\circ} \mathrm{C} .10 \mathrm{~mL}$ of the cold aqueous solution ( $0.54 \mathrm{~g}, 7.8 \mathrm{mmole})$ of $\mathrm{NaNO}_{2}$ was added to the acidic solution of 4-chloroaniline to form diazotization salt of 4 -chloroaniline. Theophylline ( $1.4 \mathrm{~g}, 7.8 \mathrm{~mole})$ was dissolved in $40 \mathrm{~mL}$ of aqueous solution of sodium hydroxide $(1.6 \mathrm{~g})$. The diazotization salt of 4 -chloroaniline was mixed with cold basic solution of theophylline. The solution was left overnight, the solution was filtrated, and the formed azo dye was dark yellow powder, yield: $60 \%$; IR $\mathrm{cm}^{-1}$ : $3371(\mathrm{~N}-\mathrm{H})$, 3105 (CH aromatic), 2919 ( $\mathrm{CH}$ aliphatic), 1705 (C=O), 1641 $(\mathrm{C}=\mathrm{N}), 1556(\mathrm{C}=\mathrm{C})$, and $1444(\mathrm{~N}=\mathrm{N})$; elemental analysis \% (C.H.N) of $\mathrm{C}_{13} \mathrm{H}_{11} \mathrm{~N}_{6} \mathrm{O}_{2} \mathrm{Cl} ; \mathrm{C}=48.56$ (cal. 48.99), $\mathrm{H}=3.35$ (cal. 3.48), and $\mathrm{N}=26.31$ (cal. 26.37); and m.p. $270^{\circ} \mathrm{C}$.

The coordination compounds of cobalt and nickel (divalent) for CPAT dye were synthesized by reacting hot aqueous solution $(10 \mathrm{~mL})$ having 0.3 mmole of these salts in each case with $15 \mathrm{~mL}$ hot ethanol having $(0.2222 \mathrm{~g}$, $0.3 \mathrm{mmole}$ ) of CPAT dye. The mixture of reaction was stirred for one hour, and then the solution was filtrated: $\mathrm{Co}$ (II) complex: 80\% yield, brown powder; IR cm ${ }^{-1}$ : $3444(\mathrm{~N}-\mathrm{H})$, 3064 ( $\mathrm{CH}$ aromatic), 2900 ( $\mathrm{CH}$ aliphatic), 1653 (C=O), 1606 $(\mathrm{C}=\mathrm{N}), 1531(\mathrm{C}=\mathrm{C})$, and $1417(\mathrm{~N}=\mathrm{N})$; elemental analysis \% (C.H.N) of $\mathrm{C}_{26} \mathrm{H}_{22} \mathrm{~N}_{12} \mathrm{O}_{4} \mathrm{Cl}_{4} \mathrm{Co} ; \mathrm{C}=40.58$ (cal. 40.70), $\mathrm{H}=2.75$ (cal. 2.89), and $\mathrm{N}=21.83$ (cal. 21.91); and m.p. more $375^{\circ} \mathrm{C}$, as well as $\mathrm{Ni}(\mathrm{II})$ complex: $75 \%$ yield, yellowish green powder; IR cm ${ }^{-1}$ : $3421(\mathrm{~N}-\mathrm{H}), 3100$ ( $\mathrm{CH}$ aromatic), 2900 ( $\mathrm{CH}$ aliphatic), $1676(\mathrm{C}=\mathrm{O}), 1616(\mathrm{C}=\mathrm{N}), 1531(\mathrm{C}=\mathrm{C})$, and $1417(\mathrm{~N}=\mathrm{N})$; elemental analysis \% (C.H.N) of $\mathrm{C}_{26} \mathrm{H}_{22} \mathrm{~N}_{12} \mathrm{O}_{4} \mathrm{Cl}_{4} \mathrm{Ni}$; $\mathrm{C}=40.53$ (cal. 40.71), $\mathrm{H}=2.76$ (cal. 2.89), and $\mathrm{N}=21.73$ (cal. 21.91); and m.p. more $375^{\circ} \mathrm{C}$.

Results of bioactivity against Gram-positive and Gramnegative bacteria and fungi were performed against each of the epidermal Staphylococcus, E. coli, and Aspergillus fungi by the method of propagation on Petri dishes, using a Muller-Hinton medium for all compounds at concentrations of 100 and $50 \mathrm{mg} / \mathrm{mL}$. The damping zone diameter was determined for each trial by taking the mean for repeated three times for each trial.

\section{Results and Discussion}

In this study, azo dye of 8-(1-(4-chlorophenyl)azo)theophylline (CPAT) was synthesized by diazotization of 4 chloroaniline, then coupling the formed diazotization salt with theophylline in basic aqueous solution to form the dye as in Scheme 1.

The mass spectrum of CPAT dye is depicted in Figure 1. The CPAT dye exhibited a peak $m / z=318$ due to the mother fragment which is in agreement with expected molecular mass of the CPAT dye, and it is perfectly in agreement with C.H.N analysis of CPAT dye.

The CPAT dye was also characterized by ${ }^{1} \mathrm{H}-\mathrm{NMR}$ spectroscopy in DMSO-d6 solvent. The ${ }^{1} \mathrm{H}-\mathrm{NMR}$ spectrum of CPAT (Figure 2) exhibited five signals besides the signals of solvent and water. The first signal is resonating at $13.5 \mathrm{ppm}$ and attributed to $\mathrm{N}-\mathrm{H}$ proton. The second and third signals are the two doublet peaks attributed to the four protons (each signal is due to two protons) of the aromatic ring which are resonating at $7.8 \mathrm{ppm}$ and $7.6 \mathrm{ppm}$. The remaining fourth and fifth signals are attributed to the two methyl groups of theophylline that resonate at 3.4 and $3.2 \mathrm{ppm}$.

The XRD spectrum of CPAT dye is depicted in Figure 3 which was recorded in the $2 \theta$ range of 5-80. The position of signals $(2 \theta)$ and full width at half maximum (FWHM) of signals were detected by X'Pert HighScore program. The crystalline size average of CPAT dye is calculated by Scherer's equation $(D=0.94 \lambda / \beta \operatorname{Cos} \theta)$, the $D$ represents the particle size of the crystal gain, $\theta$ represents Bragg diffraction angle, $\lambda$ represents the $\mathrm{X}$-ray wavelength which is $1.5406 \AA$, and $\beta$ represents the integral peak width. The crystalline size average of CPAT dye is equal to $50 \mathrm{~nm}$. The XRD exhibited sharp seven signals which indicate a well-defined crystalline structure for CPAT dye. The morphology of CPAT dye was investigated by field emission scanning electron microscopy (FESEM). The FESEM image of CPAT dye (Figure 4) shows a uniform distribution of particle size. The shape of CPAT dye particles is a beard, and the average particle size of CPAT was found to be between 24.8 and $39.26 \mathrm{~nm}$, indicating that the particle size of CPAT dye is within the nanomaterial scale.

Photochromic properties of azo dyes have large application such as high optic data storage devices and photochromic inks $[25,26]$. The visible light irradiation for CPAT dye at $405 \mathrm{~nm}$ exhibited high conversion from trans $(E)$ to cis 


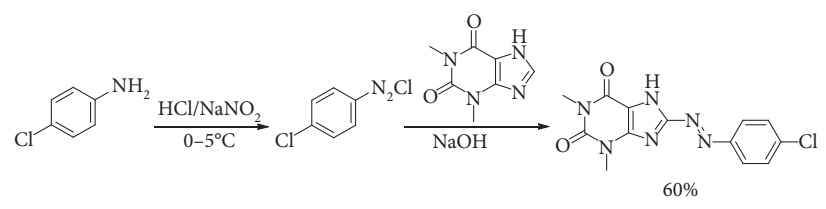

Scheme 1: Preparation steps of CPAT azo dye of theophylline.

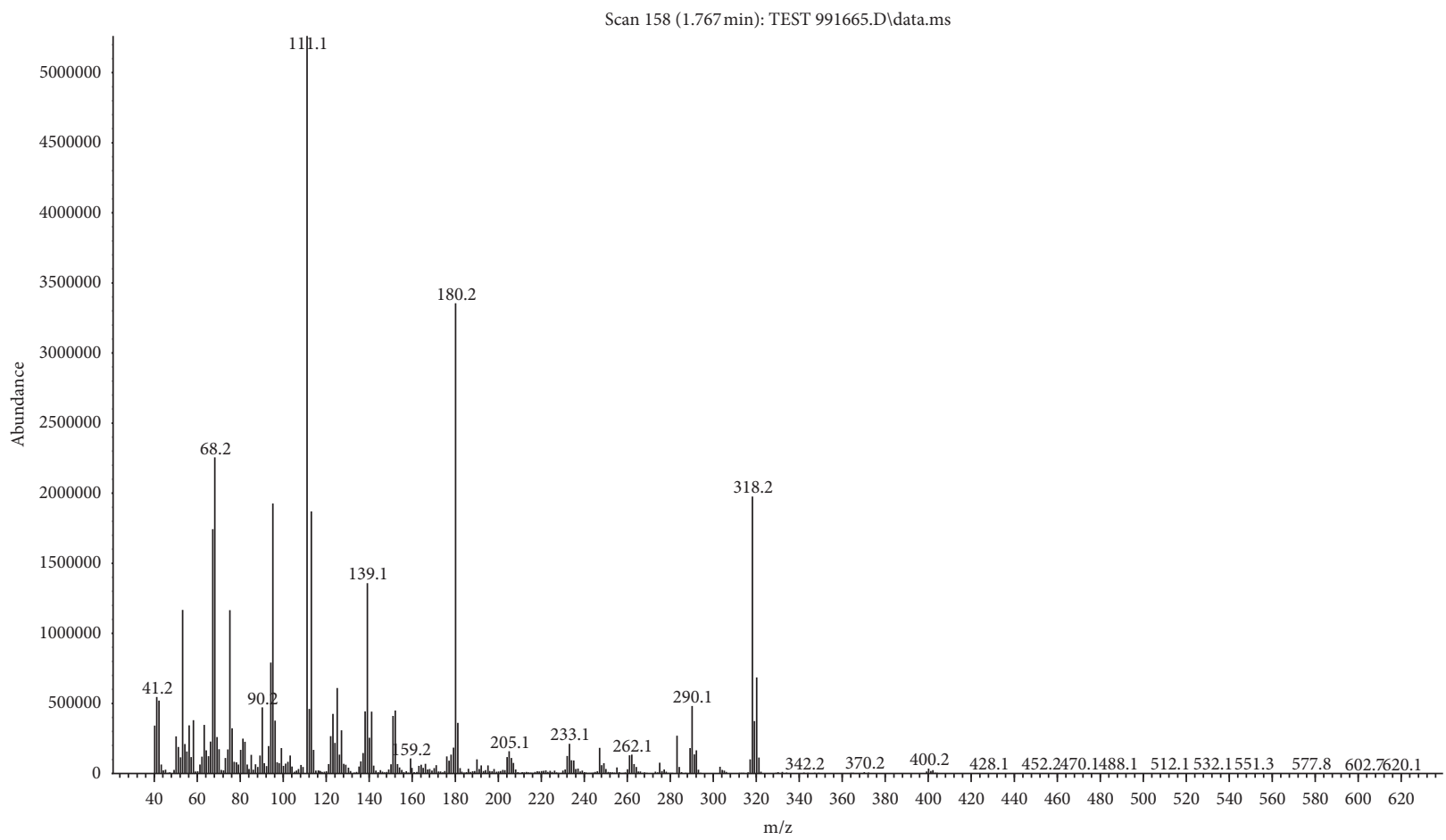

FIgURe 1: Mass spectrum of CPAT dye.

$(Z)$ geometry, and these changes were monitored by UVvisible absorption spectroscopy (Figure 5). It seems that $\pi-\pi *$ transition overlaps with $n-\pi *$ to form large band at $424 \mathrm{~nm}$ in acetone which leads to decrease energy of $\pi-\pi *$ transition and increasing chance of converting of trans to cis isomer $[9,27]$. When the dye coordinates to the metal within the complex structures, the photochromic properties will be lost [9]. In some dye complexes, the dye does not bond to the metal; therefore, it still exhibits photochromic properties. In our case, the complexes did not show photoisomerization behavior which means that the CPAT dye is bonded to the metal within complex structure. It is nice to point that the cis isomer backed totally at room temperature to trans isomer which means that the chromic behavior is intrinsic [27-32].

\subsection{Solvatochromic Studies of CPAT Dye.} Solvatochromism concept refers to change in the color by the interaction of the solvent with a solute which produces changes in the size and the shape of the UV-Vis spectra. When the solvent is compatible and suitable for the dye (solute), this gives precision to the UV-Vis spectroscopy method. The absorption spectra of $10^{-4} \mathrm{M}$ CPAT dye (Figure 6) have been recorded in four solvents having different polarities at ambient temperature. The CPAT dye in different solvents proved red shift with hyperchromic effect under decreasing the polarity from methanol, ethanol, and DMSO to acetone which let to use it as solvatochromic probe $[2,33,34]$. The CPAT dye exhibited clear absorbance shifts (hypochromic or hyperchromic) which can project a good idea of the interaction pattern between the solvent and dye (solute).

3.2. CPAT Dye and Its Complexes of $\mathrm{Co}(I I)$ and Ni(II). The complexes of CPAT with $\mathrm{Co}(\mathrm{II})$ and $\mathrm{Ni}$ (II) were synthesized in ratio of $\mathrm{M}: \mathrm{L}(1: 2)$ (Scheme 2). This ratio was confirmed by elemental analysis (C.H.N), molar conductivity, infrared spectrometry, and the visible titration of 2 equivalent dye ligand with 1 equivalent of cobalt chloride salt (Figure 7).

3.3. CPAT with $0.2 \mathrm{mM}$ Cobalt Chloride in DMSO at Room Temperature. The infrared spectra of CPAT dye and the $\mathrm{Co}(\mathrm{II})$ and $\mathrm{Ni}(\mathrm{II})$ complexes are depicted in Figures 8-10. These spectra show important characteristic peaks including stretching vibrations of $\mathrm{NH}$, aromatic $\mathrm{CH}$, aliphatic $\mathrm{CH}$, $\mathrm{C}=\mathrm{O}, \mathrm{C}=\mathrm{N}$, and $\mathrm{N}=\mathrm{N}$. We noticed that the frequencies of $\mathrm{C}=\mathrm{N}$ and $\mathrm{N}=\mathrm{N}$ groups show red shift in the complexes of 


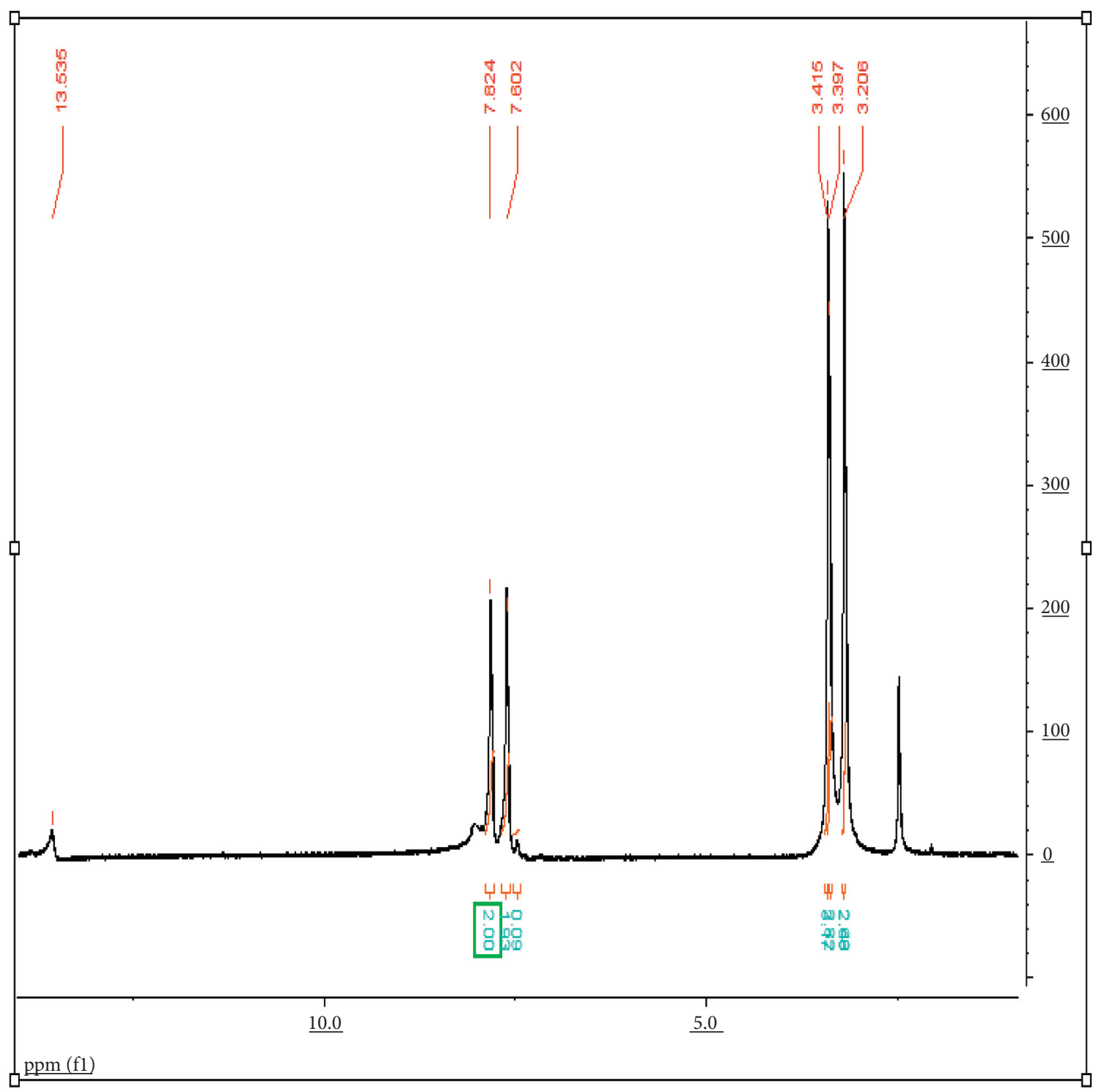

Figure 2: ${ }^{1} \mathrm{H}-\mathrm{NMR}$ spectrum of CPAT dye in DMSO-d6 at $298 \mathrm{~K}$.

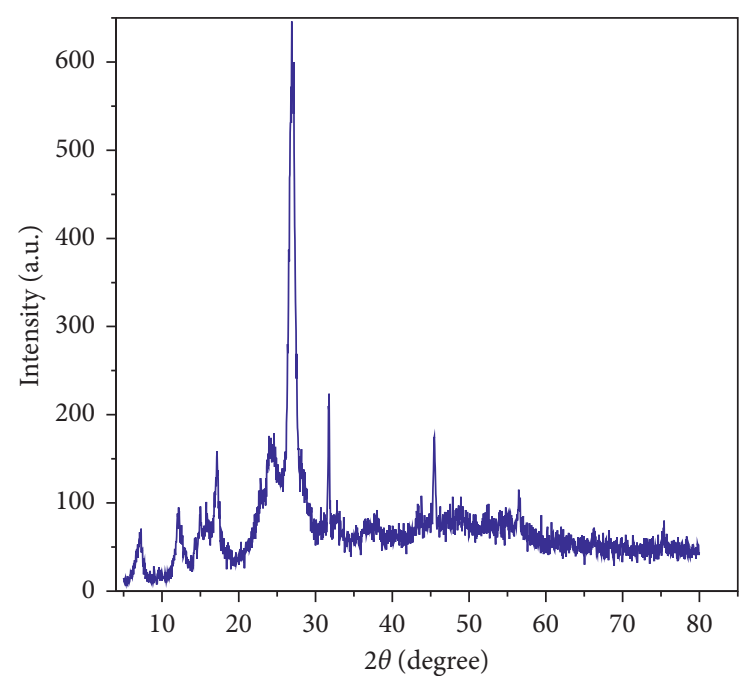

FIGURE 3: XRD spectrum of CPAT dye.

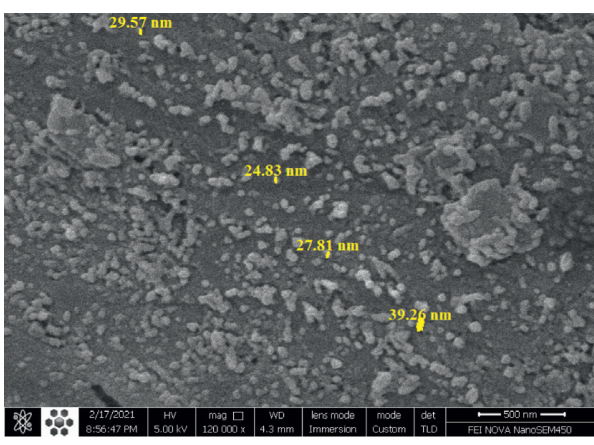

FIgUre 4: FESEM image of CPAT dye.

cobalt and nickel compared to those in the spectrum of the free CPAT ligand. The $\mathrm{C}=\mathrm{N}$ group exhibited red shift of $25 \mathrm{~cm}^{-1}$ in the spectra of cobalt and nickel complexes. The azo group $(\mathrm{N}=\mathrm{N})$ exhibits red shift of $27 \mathrm{~cm}^{-1}$ in both 


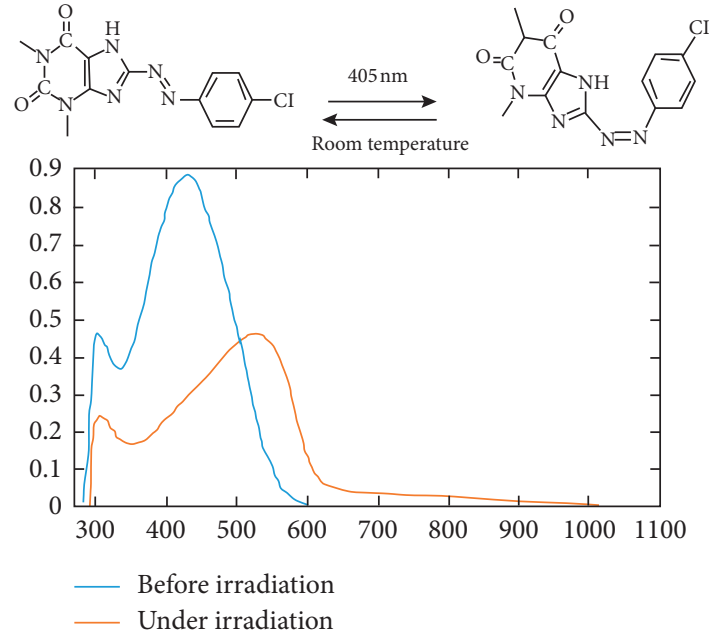

FIGURE 5: UV-visible absorption spectra of CPAT before (blue line) and under irradiation (red line) at $405 \mathrm{~nm}$ in acetone.

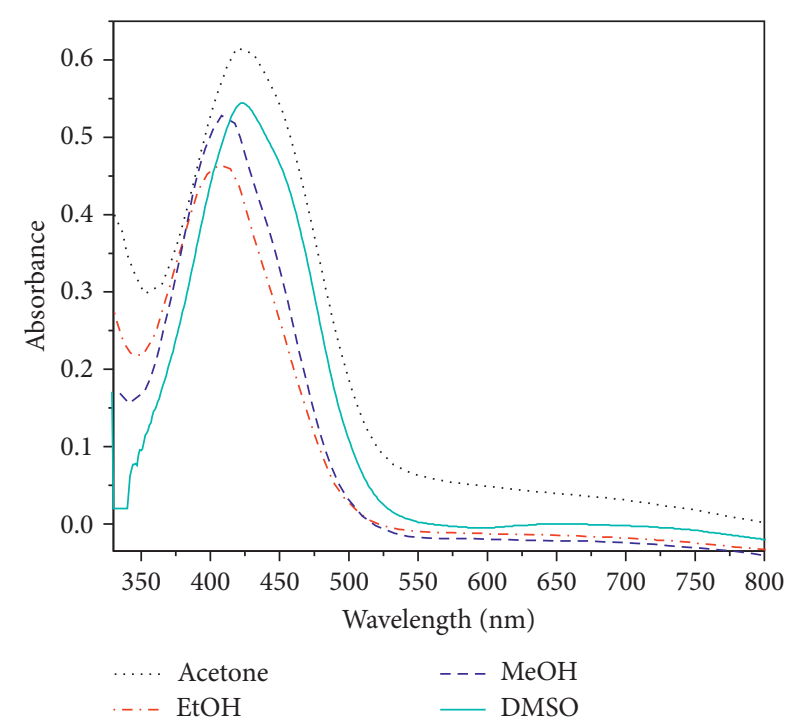

FIgURE 6: Electronic absorption spectra of $10^{-4} \mathrm{M}$ CPAT dye in different solvents at ambient temperature.

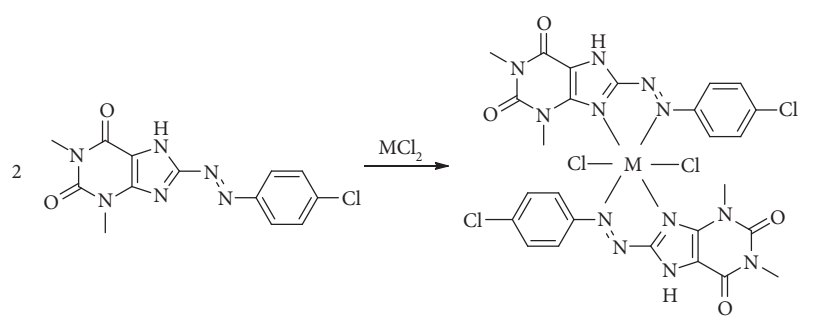

Scheme 2: Preparation of CPAT complexes for Co(II) and Ni(II).

complexes in agreement with the literature related to azo dye complexes [14, 35].

Electronic spectra of CPAT dye and the complexes were recorded in DMSO at room temperature and are depicted in Figure 11. The CPAT dye showed absorption bands at

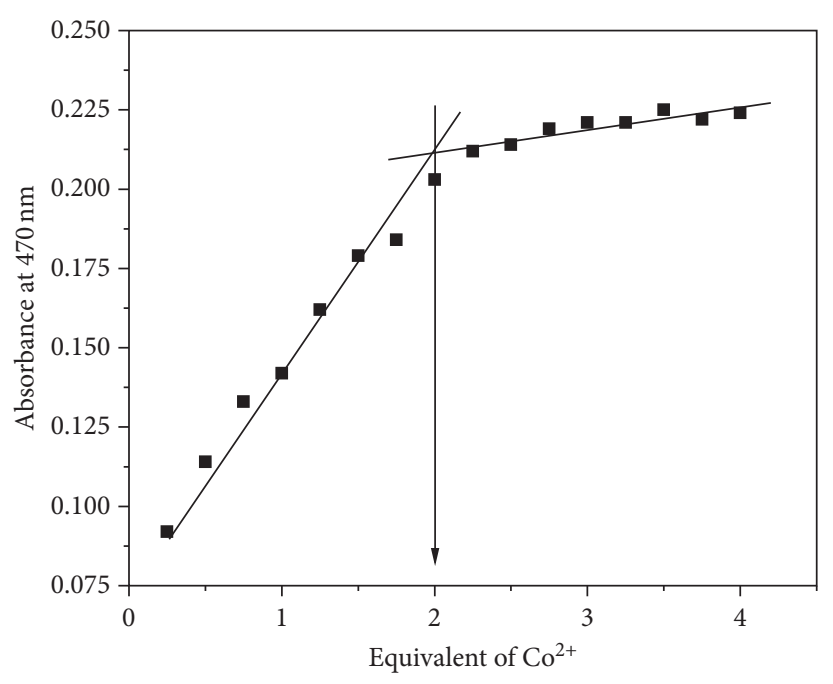

FIgURE 7: The visible absorption titration of $0.2 \mathrm{mM}$.

$280 \mathrm{~nm}$ and $350 \mathrm{~nm}$ due to $\pi-\pi^{*}$ transition and at $450 \mathrm{~nm}$ due to $n-\pi^{*}$ transition. Nickel (II) complex of CPAT dye exhibited absorption bands at $343 \mathrm{~nm}$ due to $\pi-\pi^{*}$ transition, $471 \mathrm{~nm}$ due to ${ }^{3} \mathrm{~A}_{2 \mathrm{~g}}(\mathrm{~F})$ to ${ }^{3} \mathrm{~T}_{2 \mathrm{~g}}(\mathrm{~F})$ transition, $620 \mathrm{~nm}$ due to ${ }^{3} \mathrm{~A}_{2 \mathrm{~g}}(\mathrm{~F})$ to ${ }^{3} \mathrm{~T}_{1 \mathrm{~g}}(\mathrm{~F})$ transition, and $717 \mathrm{~nm}$ due to ${ }^{3} \mathrm{~A}_{2 \mathrm{~g}}(\mathrm{~F})$ to ${ }^{3} \mathrm{~T}_{2 \mathrm{~g}}(\mathrm{P})$ transition, with a magnetic moment equal to $3.21 \mathrm{BM}$ in agreement with octahedral nickel complexes [36]. Cobalt(II) complex of CPAT dye showed absorption bands at $350 \mathrm{~nm}$ due to $\pi-\pi^{*}$ transition, $470 \mathrm{~nm}$ due to ${ }^{4} \mathrm{~T}_{1 \mathrm{~g}}(\mathrm{~F})$ to ${ }^{4} \mathrm{~T}_{2} \mathrm{~g}(\mathrm{P})$ transition, $580 \mathrm{~nm}$ due to ${ }^{4} \mathrm{~T}_{1 \mathrm{~g}}(\mathrm{~F})$ to ${ }^{4} \mathrm{~A}_{2 \mathrm{~g}}(\mathrm{~F})$ transition, and $705 \mathrm{~nm}$ due to ${ }^{4} \mathrm{~T}_{1 \mathrm{~g}}(\mathrm{~F})$ to ${ }^{4} \mathrm{~T}_{2 \mathrm{~g}}(\mathrm{~F})$ transition with magnetic moment equal to 5.01 B.M. in agreement with octahedral cobalt complexes $[35,36]$. The molar conductance of the synthesized cobalt and nickel complexes $\left(10^{-3} \mathrm{M}\right)$ were 15 and $20 \mathrm{~S} \mathrm{~cm}^{2} \mathrm{~mol}^{-1}$, respectively, in DMSO solvent which indicated that both these complexes are nonionic.

3.4. Biological Activity of CPAT and Its Complexes. Antimicrobials are critical for reducing the global burden of infectious diseases. Antimicrobial resistance is spreading around the world, reducing the efficacy of many antibiotics, particularly in immunocompromised patients. Drug resistance, especially by bacteria and fungi, is a major concern for public health and scientific communities around the world. The antimicrobial activity of CPAT dye and its complexes are performed against E. coli and Staph. aureus bacteria and Aspergillus fungi by diffusion technique. The antimicrobial data, as shown in Table 1, indicated that CPAT dye and its synthesized complexes exhibited significant biological activities against these organisms where the synthesized compounds exhibited inhibition zones from 2.5 to $3.5 \mathrm{~cm}$ against $E$. coli bacteria and 1 to $2.5 \mathrm{~cm}$ against Staph. aureus bacteria. The compounds exhibited $3-4 \mathrm{~cm}$ inhibition zones against Aspergillus fungi. The cobalt complex showed the highest activity against Aspergillus fungi (Figure 12). The complexes exhibit important biological activity comparing to CPAT dye and the 


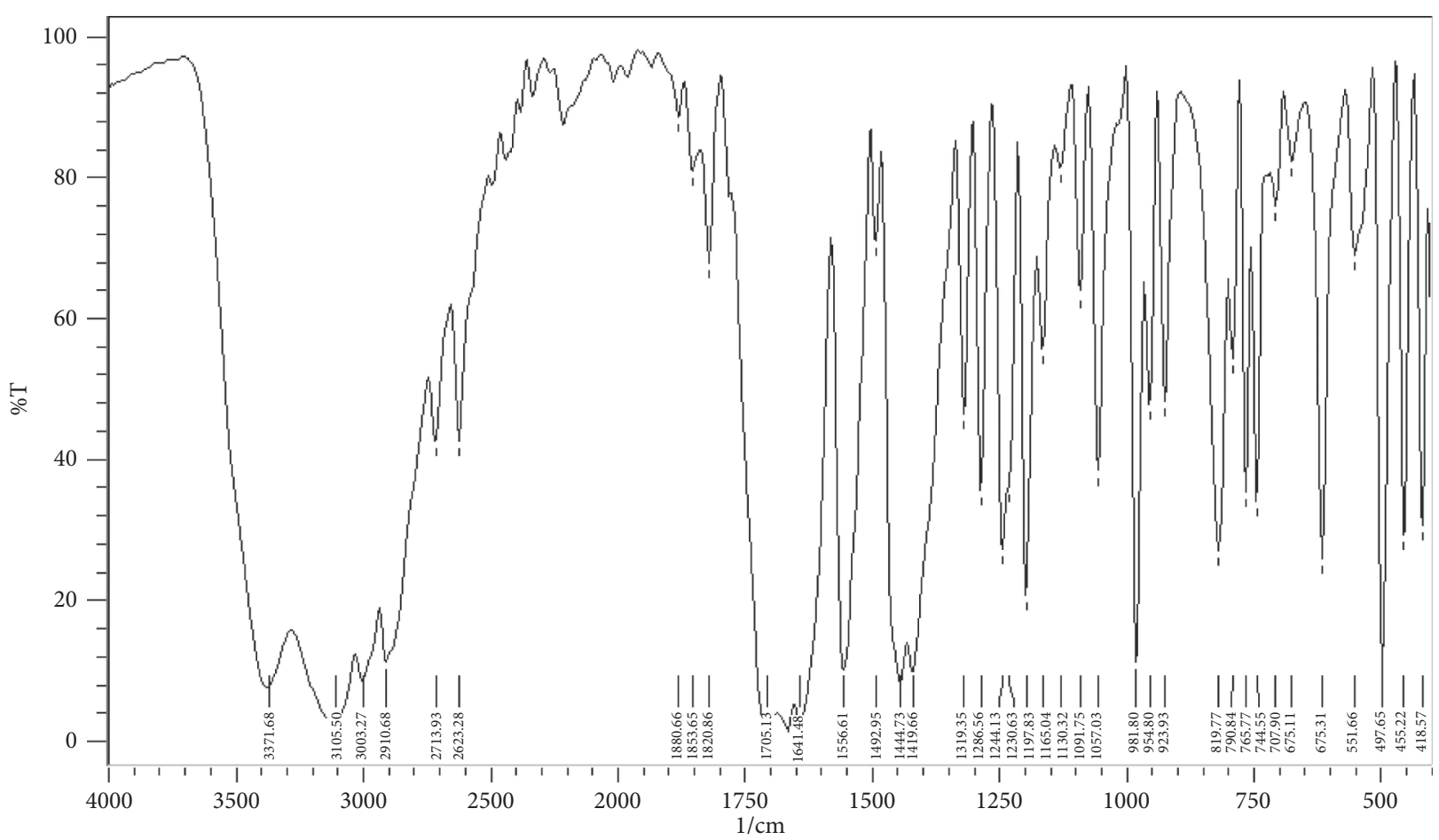

FIGURE 8: Infrared spectrum of CPAT as KBr disk.

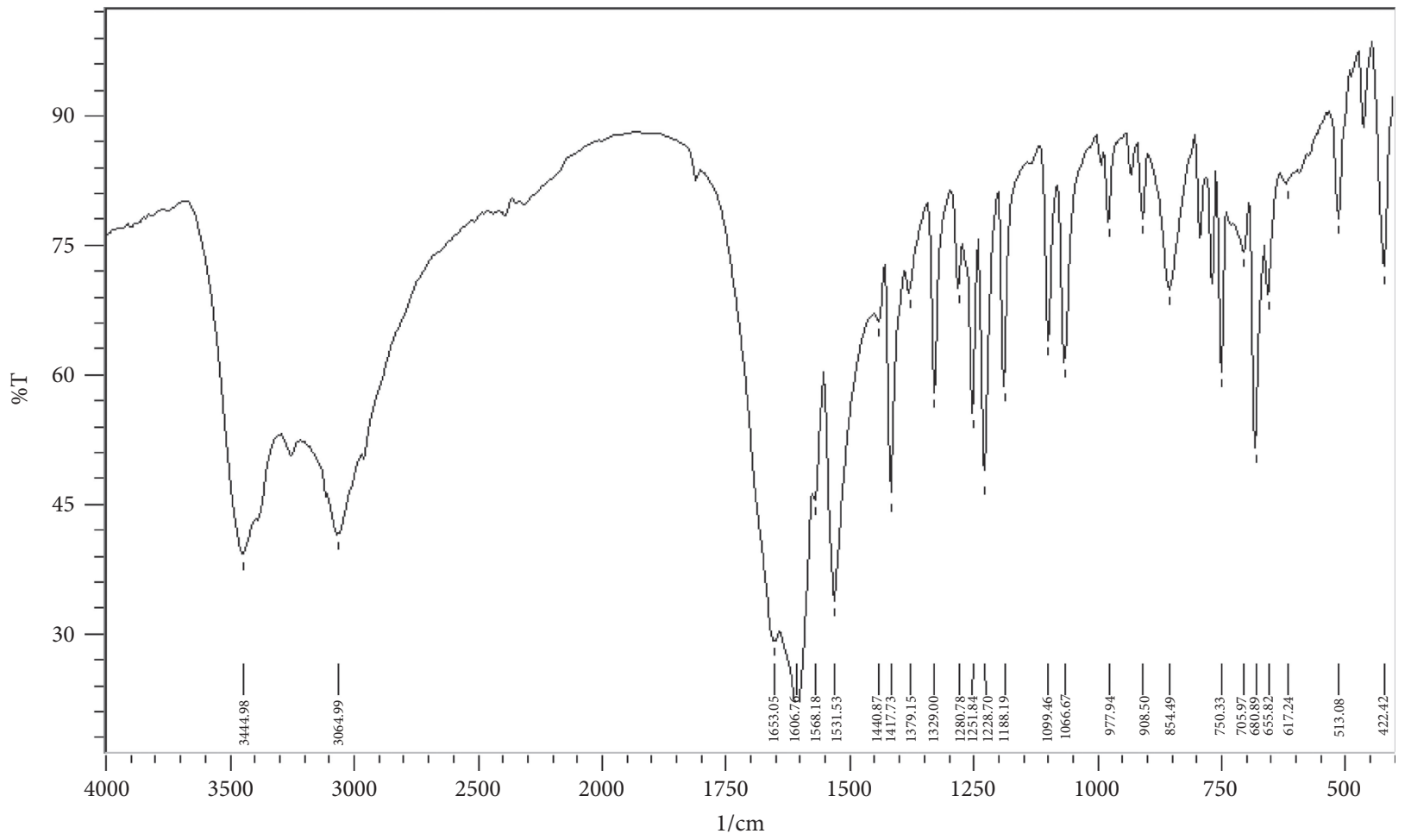

FIGURE 9: Infrared spectrum of cobalt complex as $\mathrm{KBr}$ disk.

standard drug (ciprofloxacin and fluconazole) that is possible due to the chelation in complexes which leads to a decrease in the polarity of the metal ions. This behavior increases the lipophilicity of the metals; therefore, the complexes permeate the lipid membranes of microorganisms and prevent their growth. 


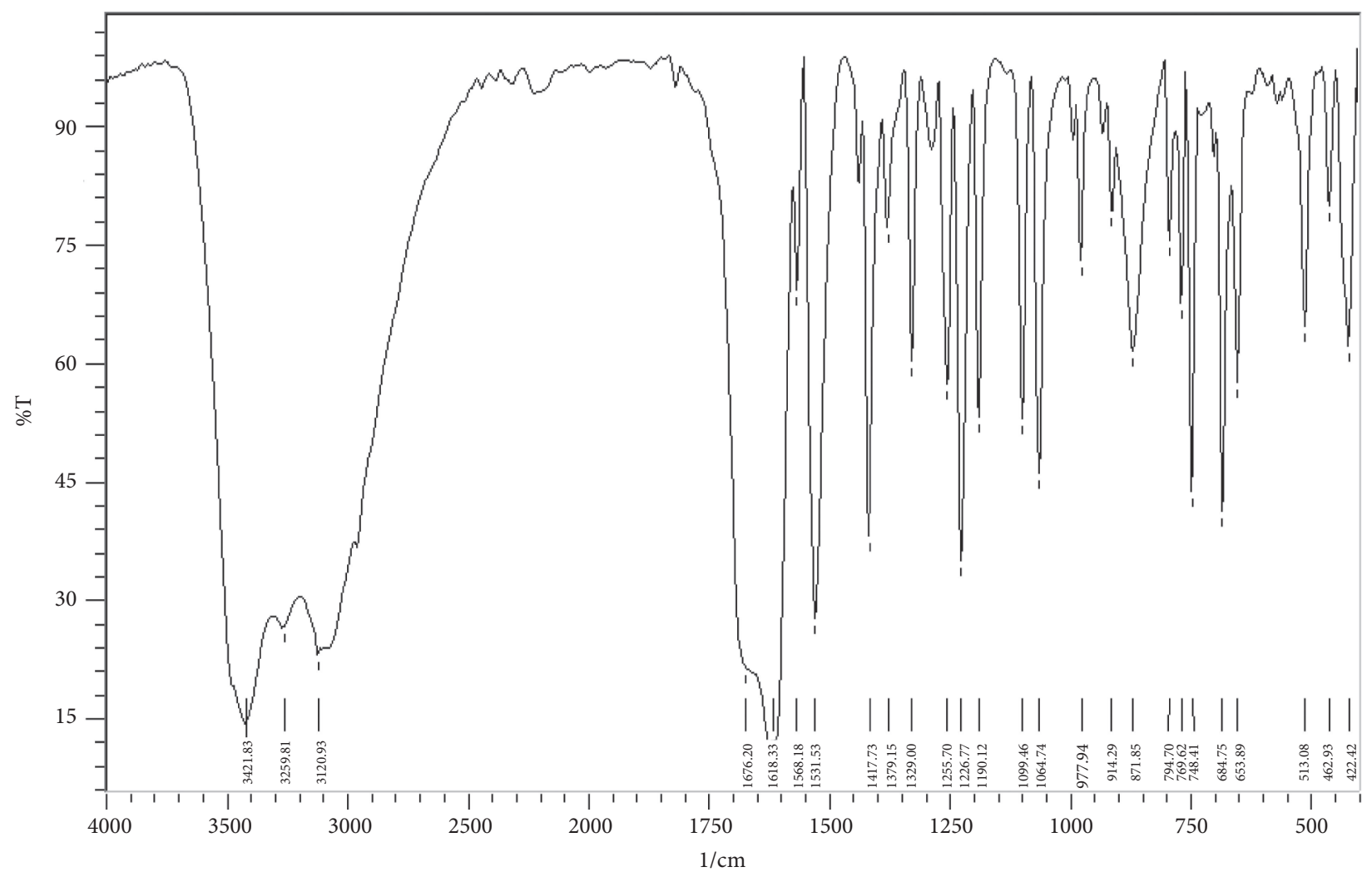

FIGURE 10: Infrared spectrum of nickel complex as KBr disk.

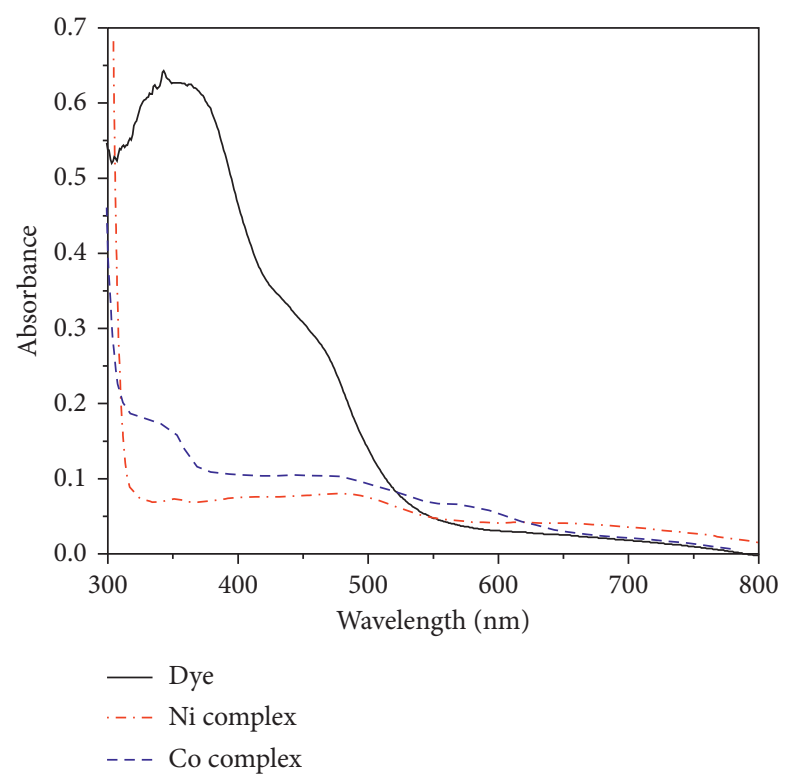

FIgURE 11: Electronic absorption spectra of CPAT, cobalt, and nickel complexes in DMSO at ambient temperature.

TABLE 1: Inhibition zone $(\mathrm{cm})$ of synthesized compounds against E. coli and Staph. aureus bacteria and Aspergillus fungi.

\begin{tabular}{lccc}
\hline Compound & E. coli & Staph. aureus & Aspergillus \\
\hline CPAT dye & 3.5 & 1 & 3 \\
Co complex & 2.5 & 2 & 4 \\
Ni complex & 3 & 2.5 & 3 \\
Ciprofloxacin & 1.5 & 2.5 & 4.5 \\
Fluconazole & & & \\
\hline
\end{tabular}




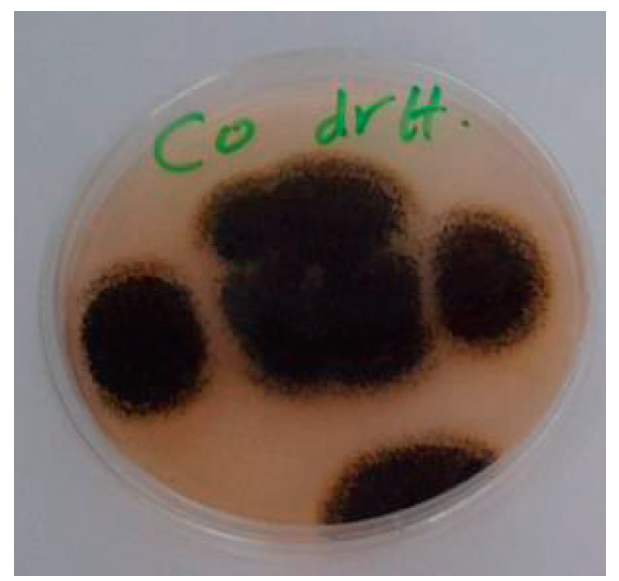

FIgURE 12: Inhibition zones of cobalt complex against Aspergillus fungi.

\section{Conclusion}

Novel azo dye of theophylline, namely, 8-(1-(4-chlorophenyl)azo)theophylline (CPAT), was prepared by coupling diazoinium salt of 4-chloroaniline with theophylline. The CPAT ligand is a good photochromic material, and it can be considered a candidate as a material for high optic data storage devices. The CPAT dye showed azo-hydrazone tautomers. The nitrogen of the azo group and nitrogen of the $\mathrm{C}=\mathrm{N}$ group of CPAT dye are coordinated to the metal ion in complexes of cobalt and nickel which means that CPAT dye is a bidentate ligand. Both the cobalt(II) and nickel(II) complexes of CPAT dye exhibited octahedral geometries. In comparison to traditional antibiotics, the synthesized compounds in our study showed promising effectiveness against Staph. aureus and E. coli bacteria and Aspergillus fungi.

\section{Data Availability}

The data used to support the findings of this study are available from the corresponding author upon request.

\section{Disclosure}

This work was performed in the laboratories of the chemistry and biology departments in Al-Qadisiyah University.

\section{Conflicts of Interest}

The author declares that there are no conflicts of interest.

\section{References}

[1] D. V. Snigur, A. N. Chebotarev, and K. V. Bevziuk, "Acid-base properties of azo dyes in solution studied using spectrophotometry and colorimetry," Journal of Applied Spectroscopy, vol. 85, no. 1, pp. 21-26, 2018.

[2] E. S. Darwish, M. A. Mosselhi, F. M. Altalbawy, and H. A. Saad, "Synthesis, acidity constants and tautomeric structure of the diazonium coupling products of 2-(benzylsulfanyl)-7H-purin-6-one in its ground and excited states," Molecules, vol. 16, no. 10, pp. 8788-8802, 2011.
[3] H. S. Mohammed and V. D. Tripathi, "Medicinal applications of coordination complexes," Journal of Physics: Conference Series, vol. 1664, Article ID 12070, 2020.

[4] H. S. Mohammed, V. D. Tripathi, A. A. Darghouth, and T. Mothhar, "Synthesis, Characterization, DFT calculation and Antimicrobial Activity of $\mathrm{Co}(\mathrm{II})$ and $\mathrm{Cu}(\mathrm{II})$ complexes with azo dye," Journal of Physics: Conference Series, vol. 1294, Article ID 52051, 2019.

[5] A. Rananaware, M. Samanta, R. S. Bhosale et al., "Photomodulation of fluoride ion binding through anion- $\pi$ interactions using a photoswitchable azobenzene system," Scientific Reports, vol. 8, no. 1, pp. 1-10, 2016.

[6] G. Hussain, N. Abass, G. Shabir et al., "New acid dyes and their metal complexes based on substituted phenols for leather: synthesis, characterization and optical studies," Journal of Applied Research and Technology, vol. 15, no. 4, pp. 346-355, 2017.

[7] S. A. Abdel-Latif and H. Moustafa, "Synthesis, characterization, electronic structure, and non-linear optical properties (NLO) of $\mathrm{Mn}(\mathrm{II}), \mathrm{Co}(\mathrm{II}), \mathrm{Ni}(\mathrm{II}), \mathrm{Cu}(\mathrm{II})$ and $\mathrm{Zn}$ (II) complexes with 5-phenylazo-8-hydroxyquinoline using DFT approach," Applied Organometallic Chemistry, vol. 31, no. 12, Article ID e3876, 2017.

[8] B. Kulyk, D. Guichaoua, A. Ayadi, A. El-Ghayoury, and B. Sahraoui, "Functionalized azo-based iminopyridine rhenium complexes for nonlinear optical performance," Dyes and Pigments, vol. 145, pp. 256-262, 2017.

[9] B. Tylkowski, R. Jastrząb, and M. Skrobańska, "Photo-sensitive complexes based on azobenzene," Physical Sciences Reviews, vol. 30, no. 4, p. 1, 2016.

[10] W. H. Mahmoud, F. N. Sayed, and G. G. Mohamed, "Synthesis, characterization andin vitroantimicrobial and antibreast cancer activity studies of metal complexes of novel pentadentate azo dye ligand," Applied Organometallic Chemistry, vol. 30, no. 11, pp. 959-973, 2016.

[11] C. K. Manna, R. Naskar, and T. K. Mondal, "Palladium(II) complex with 1-(2-pyridylazo)-2-naphthol (PAN): synthesis, $\mathrm{X}$-ray structure, electrochemistry, DFT computation and DNA binding study," Journal of the Indian Chemical Society, vol. 96, no. 5, pp. 599-606, 2019.

[12] B. Abd El-Wahaab, K. Elgendy, and A. El-didamony, "Synthesis and characterization of new azo-dye reagent and using to spectrophotometric determination of samarium(III) in some industrial and blood samples," Chemical Papers, vol. 74, no. 5, pp. 1439-1448, 2020. 
[13] P. O. Abate, M. Sottile, I. E. León, M. M. Vergara, and N. E. Katz, "A symmetrical dirhenium(I) complex with 4,4"Azobis(2,2'-bipyridine) as a bridging ligand: synthesis, physicochemical properties and applications in detection of biologically relevant thiols and in chemotherapy for bone cancer," Journal of the Brazilian Chemical Society, vol. 31, no. 11, pp. 2299-2306, 2020.

[14] M. Bouhdada, M. E. Amane, and N. El Hamzaoui, "Synthesis, spectroscopic studies, X-ray powder diffraction data and antibacterial activity of mixed transition metal complexes with sulfonate azo dye, sulfamate and caffeine ligands," Inorganic Chemistry Communications, vol. 101, pp. 32-39, 2019.

[15] T. Kallio, J. Kekkonen, and P. Stenius, "Acid/base properties and adsorption of an azo dye on coating pigments," Journal of Dispersion Science and Technology, vol. 27, no. 6, pp. 825-834, 2006.

[16] N. M. Mallikarjuna and J. Keshavayya, "Synthesis, spectroscopic characterization and pharmacological studies on novel sulfamethaxazole based azo dyes," Journal of King Saud University-Science, vol. 32, no. 1, pp. 251-259, 2020.

[17] M. N. Matada and K. Jathi, "Pyrazole-based azo-metal(II) complexes as potential bioactive agents: synthesis, characterization, antimicrobial, anti-tuberculosis, and DNA interaction studies," Journal of Coordination Chemistry, vol. 72, no. 12, pp. 1994-2014, 2019.

[18] W. Piao, K. Hanaoka, T. Fujisawa et al., "Development of an azo-based photosensitizer activated under mild hypoxia for photodynamic therapy," Journal of the American Chemical Society, vol. 139, no. 39, pp. 13713-13719, 2017.

[19] M. H. Kaulage, B. Maji, S. Pasadi, S. Bhattacharya, and K. Muniyappa, "Novel ruthenium azo-quinoline complexes with enhanced photonuclease activity in human cancer cells," European Journal of Medicinal Chemistry, vol. 139, pp. 1016-1029, 2017.

[20] V. Juvekar, C. S. Lim, D. J. Lee et al., "An azo dye for photodynamic therapy that is activated selectively by two-photon excitation," Chemical Science, vol. 12, no. 1, pp. 427-434, 2021.

[21] L. Zeng, S. Kuang, G. Li, C. Jin, L. Ji, and H. Chao, "A GSHactivatable ruthenium(ii)-azo photosensitizer for two-photon photodynamic therapy," Chemical Communications, vol. 53, no. 12, pp. 1977-1980, 2017.

[22] K. Ntrallou, H. Gika, and E. Tsochatzis, "Analytical and sample preparation techniques for the determination of food colorants in food matrices," Foods, vol. 9, no. 1, p. 58, 2020.

[23] H. S. Mohammed, "Preparation and characterization of 4-[6(purinyl)azo]-1-naphthol and some transition metal complexes," Iraqi National Journal Of Chemistry, vol. 2011, no. 43, pp. 347-360, 2011.

[24] M. Clark, Handbook of Textile and Industrial Dyeing: Principles, Processes and Types of Dyes, Elsevier, Amsterdam, Netherlands, 2011.

[25] S. Crespi, N. A. Simeth, and B. König, "Heteroaryl azo dyes as molecular photoswitches," Nature Reviews Chemistry, vol. 3, no. 3, pp. 133-146, 2019.

[26] S. Dur, I. Husein, M. I Kadhim et al., “An optimally solving dentistry internal purity in heat polymerized acrylic resin with different polymerization methods," Systematic Reviews in Pharmacy, vol. 11, no. 3, pp. 974-980, 2020.

[27] H. Agarkar, D. Dave, and D. Das, "Transition metal complexes incorporated with photoswitchable azo-based benzimidazole ligands: photochromic and solvatochromic studies," Spectrochimica Acta. Part A, Molecular and Biomolecular Spectroscopy, vol. 242, Article ID 118735, 2020.
[28] S.-W. Oh, J.-M. Baek, S.-H. Kim, and T.-H. Yoon, "Optical and electrical switching of cholesteric liquid crystals containing azo dye," RSC Advances, vol. 7, no. 32, pp. 19497-19501, 2017.

[29] H. S. Mohammed, M. Tassé, I. Malfant, and L. Vendier, "cisChlorido-bis-(4,4'-dimethyl-2,2' -bi-pyridine)-nitro-sylruthenium(II) bis-(hexa-fluoro-phosphate)," IUCrData, vol. 28, no. 7, Article ID x171013, 2017.

[30] M. Tassé, H. S. Mohammed, C. Sabourdy, S. Mallet-Ladeira, P. G. Lacroix, and I. Malfant, "Synthesis, crystal structure, spectroscopic, and photoreactive properties of a ruthenium(II)-mononitrosyl complex," Polyhedron, vol. 119, pp. 350-358, 2016.

[31] H. Shamran Mohammed, S. Mallet-Ladeira, B. Cormary, M. Tassé, and I. Malfant, "trans-Chlorido-tetra-kis-(4-methylpyridine- $\kappa \mathrm{N}$ )(nitrosyl- $\kappa \mathrm{N}$ )ruthenium(II) bis-(hexa-fluoridophosphate) acetone 0.75-solvate," IUCrData, vol. 2, no. 12, Article ID x171761, 2017.

[32] H. S. Mohammed, "Synthesis, characterization, structure determination from powder X-ray diffraction data, and biological activity of azo dye of 3-aminopyridine and its complexes of $\mathrm{Ni}(\mathrm{II})$ and $\mathrm{Cu}(\mathrm{II})$, , Bulletin of the Chemical Society of Ethiopia, vol. 34, no. 3, pp. 523-532, 2020.

[33] K. T. Mahmudov, A. M. Maharramov, R. A. Aliyeva et al., "3(para-Substituted phenylhydrazo)pentane-2,4-diones: physicochemical and solvatochromic properties," Journal of Photochemistry and Photobiology A: Chemistry, vol. 219, no. 1, pp. 159-165, 2011.

[34] M. A. Davasaz Rabbani, B. Khalili, and H. Saeidian, "Novel edaravone-based azo dyes: efficient synthesis, characterization, antibacterial activity, DFT calculations and comprehensive investigation of the solvent effect on the absorption spectra," RSC Advances, vol. 10, no. 59, pp. 35729-35739, 2020.

[35] S. A. Shaker, Y. Farina, and S. Mahmmod, "Synthesis and characterization of mixed ligand complexes of caffeine, adenine and thiocyanate with some transition metal ions," Sains Malaysiana, vol. 39, no. 6, pp. 957-962, 2010.

[36] K. D. Patel and H. S. Patel, "Synthesis, spectroscopic characterization and thermal studies of some divalent transition metal complexes of 8-hydroxyquinoline," Arabian Journal of Chemistry, vol. 10, pp. S1328-S1335, 2017. 